\title{
Article
}

\section{Efficiency, energy and stoichiometry in pelagic food webs; reciprocal roles of food quality and food quantity}

\author{
Dag O. Hessen
}

University of Oslo, Dept. of Biology, Center of Ecological and Evolutionary Synthesis (CEES), P.O. Box 1066 Blindern, 0316 Oslo, Norway. Email: dag.hessen@bio.uio.no

Received 25 June 2007; accepted 26 September 2007; published 28 January 2008

\section{Abstract}

In most lakes, zooplankton production is constrained by food quantity, but frequently high C:P poses an additional constraint on zooplankton production by reducing the carbon transfer efficiency from phytoplankton to zooplankton. This review addresses how the flux of matter and energy in pelagic food webs is regulated by food quantity in terms of $C$ and its stoichiometric quality in terms of C:P. Increased levels of light, $\mathrm{CO}_{2}$ and phosphorus could each increase seston mass and, hence, food quantity for zooplankton, but while light and $\mathrm{CO}_{2}$ each cause increased C:P (i.e. reduced food quality for herbivores), increased $\mathrm{P}$ may increase seston mass and its stoichiometric quality by reducing C:P. Development of food quality and food quantity in response to C- or P-enrichments will differ between 'batch-type' lakes (dominated by one major, seasonal input of water and nutrients) and 'continuous-culture' types of lakes with a more steady flow-rate of water and nutrients. The reciprocal role of food quantity and stoichiometric quality will depend strongly on facilitation via grazing and recycling by the grazers, and this effect will be most important in systems with low renewal rates. At high food abundance but low quality, there will be a 'quality starvation' in zooplankton. From a management point of view, stoichiometric theory offers a general tool-kit for understanding the integrated role of $\mathrm{C}$ and $\mathrm{P}$ in food webs and how food quantity and stoichiometric quality (i.e. C:P) regulate energy flow and trophic efficiency from base to top in food webs.

Keywords: Food quantity; food quality; carbon; phosphorus; lakes; light; stoichiometry.

\section{Introduction}

Why do populations not grow infinitely? The general wisdom is that they are constrained by predators, diseases or shortage of food. One classical argument has been that 'the world is green' due to top-down control, meaning that the herbivores are sufficiently controlled by their predators to leave plenty of vegetation behind (Hairston et al., 1960;
Oksanen, 1988). For freshwater ecosystems, the discussion of whether members of the plankton community, either phyto- or zooplankton, are controlled by top-down mechanisms (i.e. by their grazers or predators respectively) or bottom-up controlled by nutrients like nitrogen $(\mathrm{N})$ and phosphorus $(\mathrm{P})$, has been especially related to the problem of eutrophication (Gulati et al., 1990; Carpenter \& Kitchell, 1993; Carpenter et al., 2001). While there has 
been for decades consensus that the production and biomass of phytoplankton in most temperate lakes is primarily governed by the ambient concentrations of $\mathrm{P}$ (Schindler, 1977), the regulation of production and biomass of zooplankton has been seen to be more subtle. Without doubt, large-bodied zooplankton can be controlled by fish predation, but to what extent are herbivorous zooplankton limited by the quantity or quality of food? We know from human experience that the short reply is that surely both quantity and quality matters. One may indeed gain biomass by consuming junk-food, rich in carbohydrates, but this does not support fitness in any sense-both quality and quantity matter.

This type of 'both matter' reply is, however, not very rewarding intellectually. We would like to know under what circumstances is quantity more important than quality, and vice versa. Are these two measures of food interrelated? And what do we actually mean by quality? Lessons from human nutritional studies may have limited value for judging food quality and quantity in invertebrate herbivores. I shall here address the role of food quantity and quality for pelagic consumers, building on stoichiometric perspectives.

What exactly does this mean? Different organisms are built by essentially the same kinds of macromolecules, yet the proportions of these major constituents may vary both between and within organisms. At a yet more fundamental level, basic macromolecules such as lipids, carbohydrates, proteins and nucleic acids are made up primarily by oxygen $(\mathrm{O})$, hydrogen $(\mathrm{H})$, carbon $(\mathrm{C})$, nitrogen $(\mathrm{N})$ and phosphorus $(\mathrm{P})$ in various proportions. Lipids and carbohydrates are particularly rich in $\mathrm{C}$, proteins are rich in $\mathrm{N}$ and nucleic acids are rich in $\mathrm{P}$ etc. Hence, differing biochemical organismic makeup will result in different elemental ratios. Different organisms will thus have different demands for various elemental building blocks for various biochemical purposes, and in growing organisms, there may be a subtle balance between the needs for $\mathrm{C}, \mathrm{N}$ and $\mathrm{P}$ to optimise protein synthesis and thus growth rate (Hessen et al., 2007).

In the context of ecological stoichiometry (Sterner \& Elser, 2002), the different demands of producers (like phytoplankton) and consumers (like zooplankton) have been addressed in particular. There is commonly a pronounced difference in what is 'offered' by plants, and what is 'demanded' by the consumer in terms of elements and elemental composition. In fact, this could be seen as a defence strategy for the plants (Moran \& Hamilton, 1980; White, 1993). This stoichiometric mismatch can be exemplified by comparing the elemental compositions (as $\%$ of dry weight - DW) of seston (the fine particulate matter that constitute the food of zooplankton) and zooplankton in the Dutch Lake Vuntus (Fig. 1). While the relative content of $\mathrm{C}, \mathrm{H}$ and $\mathrm{O}$ does not differ substantially, and $\mathrm{N}$ is only marginally higher in zooplankton, the difference in $P$ is striking. The data represent monthly samples over three consecutive years, and the variability in the relative contribution of elements reflect seasonal variation and community shifts, since various species also differ in their P-content. Both the absolute and relative concentrations of $\mathrm{C}$ and $\mathrm{P}$ in seston (food) and the difference in C:P between food and consumer will be an important determinant of trophic efficiency and, thus, the proportion of energy and carbon that is eventually transferred from autotrophs at the base of the food web to higher trophic levels.

\section{Autotroph biomass and stoichiometry}

Phytoplankton or, more correctly, seston in lakes show a pronounced variability in their ratios of carbon to phosphorus (C:P) both between and within localities, but are generally more C-rich compared with marine systems (Hecky et al., 1993; Elser \& Hassett, 1994; Sterner \& Elser, 2002). Various biotic and abiotic causes have been advocated for the more than 10-fold variation in seston C:P (see Hessen, 2006).

The role of light intensity for phytoplankton C:P-ratio has been verified in several studies. Shifts in the intensity of photosynthetic active radiation (PAR), especially at low concentrations of $\mathrm{P}$, may yield cellular C:P-ratios that span more than an order of magnitude due to a disproportionately high uptake of $\mathrm{C}$ relative to $\mathrm{P}$ at high light (Urabe \& Sterner, 1996; Sterner et al., 1997; Hessen et al., 2002). This 
could be a common scenario in many oligotrophic lakes, in particular during summer, when water transparency is high and there is a general shortage of inorganic,

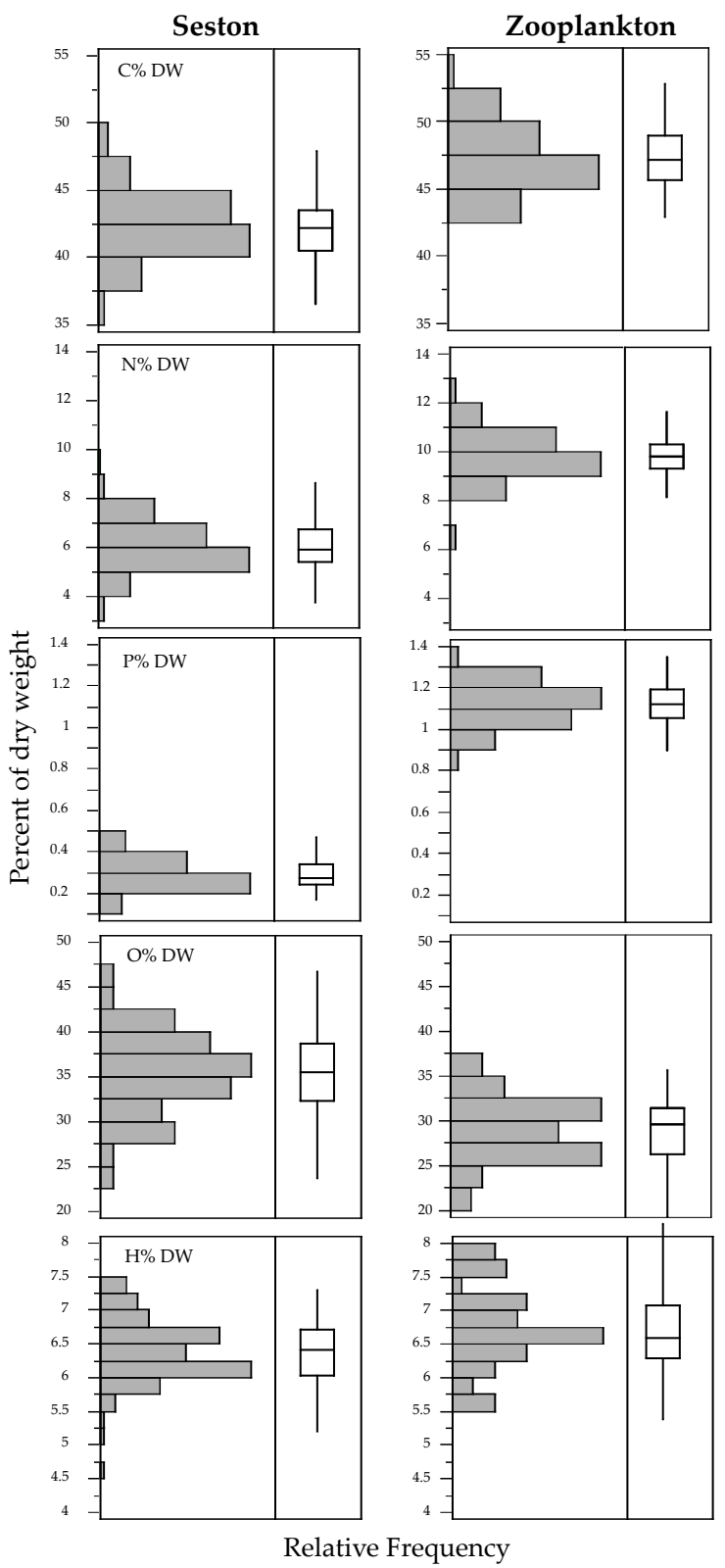

Fig. 1. Frequency distributions of the relative contributions of $C, N$, $\mathrm{P}, \mathrm{O}$ and $\mathrm{H}$ to the mass of seston and zooplankton of Lake Vuntus, Netherlands (data obtained with courtesy of Ellen van Donk, see Hessen et al., 2005). Bars represent the frequency of observations (monthly over 3 years). Right panels represent median (horizontal line), $25 \%$ confidence interval (box) and $95 \%$ confidence interval (vertical lines). bioavailable P. Large scale experiments with both plankton towers (Sterner et al., 1998) and lake enclosures with shading and P-additions (Elser et al., 2002; Urabe et al., 2002) have confirmed the stoichiometric outcome predicted by laboratory experiments. By calculating a ratio of light:P for a number of lakes, putting mixed-layer mean light in the numerator and total $\mathrm{P}$ concentration in the denominator, Sterner et al. (1997) were able to demonstrate that the light:P ratio was strongly correlated with the C:P ratio of seston. Mixing depth will strongly affect both biomass and elemental ratio of autotrophs, since there will be less light available through large mixing depths (Huismann et al., 1999; Diehl et al., 2002; Berger et al., 2006). Data on mixing depth and light attenuation can be hard to obtain for a large number of lakes, but lake area may serve as a good proxy of mixing depth, and thus there is a causal link between elemental ratios and lake size (Sterner et al., 1997; Kunz \& Diehl, 2003).

Elevated $\mathrm{CO}_{2}$ concentrations may likewise cause increased C:P-ratios due to elevated C-fixation that is not accompanied by increased uptake of $\mathrm{P}$. Inorganic $\mathrm{C}$ is abundant in water and, so, at first sight, any increase in concentration resulting from anthropogenic $\mathrm{CO}_{2}$ emissions might be expected to have little impact on phytoplankton growth. However, carbon cycling is intimately related to nutrient supply and stoichiometry. Surface waters have commonly been considered sinks for atmospheric $\mathrm{CO}_{2}$, yet recent data rather suggest that at least lakes are commonly net exporters of $\mathrm{CO}_{2}$ (Hessen et al., 1990; del Giorgio \& Peters, 1994; Sobek et al., 2003). While this is to some extent governed by the $\mathrm{pCO}_{2}$ gradients in partial pressure across the water-air boundary layer, biological processes and stoichiometric balance will be major determinants of net $\mathrm{CO}_{2}$ balance. Freshwater systems are also prone to large variations in $\mathrm{CO}_{2}$, and even a moderate increase in $\mathrm{CO}_{2}$ could yield increased C:P ratios in algae (Urabe et al., 2003; Hessen et al., 2004).

Also, the fraction of detritus may be a major determinant of seston C:P. Previous estimates from a wide span of lakes have indicated that, in general, live phytoplankton contribute less than $25 \%$ to total seston C and rarely more than $40 \%$ (Hessen et al., 2003). The 
remaining fraction of the seston will be primarily detrital (dead organic matter), although unicellular heterotrophs (bacteria and microzooplankton) also contribute to nonalgal seston, especially in systems with high allochthonous inputs. Clearly, catchment properties, residence time and geographic location could also play significant roles for sestonic C:P-ratios. Hecky et al. (1993), for example, found that lakes with short residence times had lower C:P (average 330) compared with those that had longer residence times (416). They also found a latitudinal effect where the average C:P (and N:P) ratio was higher for temperate lakes than for arctic and sub-arctic lakes. This latitudinal trend could reflect differences in soil properties, irradiation or temperature and thus mixing regimes. Southern temperate lakes may be heated more rapidly and stratified for longer periods. This could also promote shallower and more light-exposed epilimnia and, thus, higher C:P-ratios in such lakes.

Based on an analysis of seston C:P-ratios in a large number of Norwegian lakes, Hessen (2006) identified three major drivers for sestonic C:P-ratios: the share of detritus in seston, the light climate and, first and foremost, the total-P content, which is the main driver of most other parameters. The unexplained variance in seston C:P-ratios, however, was large.

\section{C versus $\mathbf{P}$ enrichment scenarios}

Now, in a quantity-or-quality context, what is the role of 'C-enrichment' by elevated PAR or $\mathrm{CO}_{2}$ ? In flow-through systems with fixed renewal rate and fixed concentrations of $\mathrm{P}$, an increase in light or $\mathrm{CO}_{2}$ from sub-saturated levels will imply that there is dilution through growth of the internal pool of $\mathrm{P}$ in phytoplankton cells. Autotroph biomass will increase in terms of dry weight or $\mathrm{C}$ but not in terms of $\mathrm{P}$, hence the C:P-ratio will increase (Fig. 2, upper panel). By keeping light or $\mathrm{CO}_{2}$ constant but elevating Pconcentrations in the medium, however, the system not only supports an increase in biomass but also in its quality (increased cell-specific P-content). Note that while flowthrough systems will stabilise at a fixed C:P depending on P concentration, light level, $\mathrm{CO}_{2}$, and flow rate, closed batch-type systems will behave differently. In a closed system, a pulsed addition of $\mathrm{P}$ would cause an immediate decrease in C:P due to 'luxury' uptake by the algae. There would then follow an asymptotic increase in C:P over time with increased biomass based on a finite amount of $\mathrm{P}$ (again, the 'growth by dilution'). In the absence of recycling, such closed systems will eventually collapse.

Enrichment with inorganic $\mathrm{C}$ or $\mathrm{P}$ will thus each potentially yield increased autotroph biomass, but with contrasting effects on C:P-ratios. Increased solar energy input or increased $\mathrm{CO}_{2}$ could each cause a 'paradox of energy enrichment' (see Sterner et al., 1997; Diehl, 2007) in that grazers are negatively impacted by increased plant biomass because of reduced stoichiometric quality. During $\mathrm{P}$ enrichment, however, both biomass and stoichiometric quality will be elevated. This is not to say that increased $P$ causes a more efficient energy-flux, since eutrophication (P enrichment) of lakes will also induce

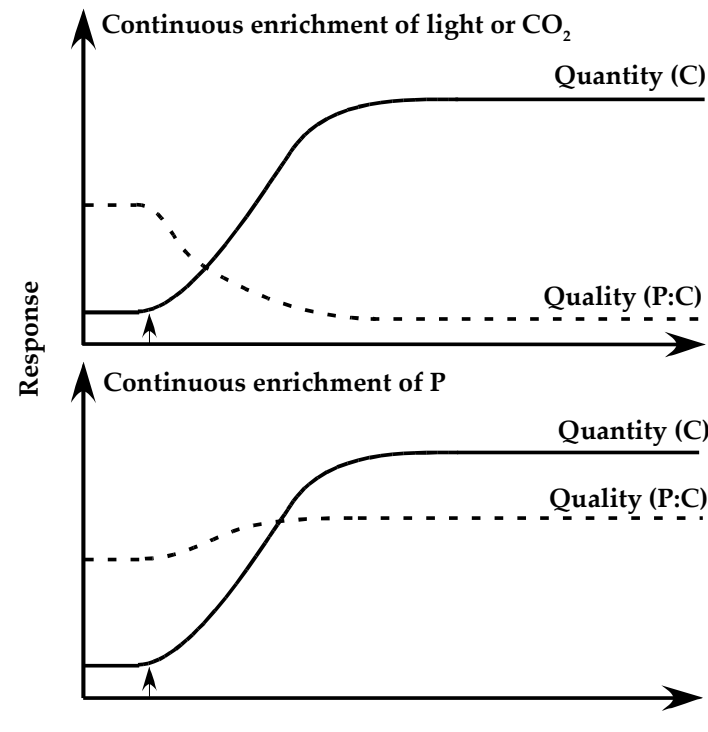

Time

Fig. 2. Conceptual diagrams for the qualitative and quantitative effects on autotrophs of enrichment scenarios in continuous cultures. Upper: the effects of 'energy enrichment' by elevated light or $\mathrm{CO}_{2}$ over time. Increased uptake rates of $\mathrm{C}$ at fixed concentration of $\mathrm{P}$ will cause elevated biomass by dilution of cellular P, hence the P:C-ratio will decrease (note that food quality here is plotted as $\mathrm{P}: \mathrm{C}$ to illustrate better the dilution effect). Lower: permanent increase in P-load will cause both elevated biomass and elevated P:C. Onset of enrichment is illustrated by arrow. 
well-described systematic shifts in autotroph composition (Jeppesen et al., 2000, 2003; Hessen et al., 2006) that will be superimposed on the stoichiometric effects. The general effect of P enrichment at the lake level seems nevertheless to be improved stoichiometric quality in more productive systems, since there is a negative correlation between seston mass and C:P (Fig. 3a). This seems to be a general phenomenon for both lakes and marine systems (Sterner et al., 2008). Correspondingly, seston C:P decreases with increasing total $\mathrm{P}$ (Fig. 3b), demonstrating that more nutrient rich lakes also have better stoichiometric seston quality.

Lakes represent a continuum between the batch-type and the continuous-culture type, where the first type is characterised by a major input of nutrient-rich waters during spring (for northern lakes this would typically occur during the snowmelt period) followed by a drier season, while the other type receives a more steady input of water and $\mathrm{P}$ during the growth season. The water renewal rate, which is analogous to the dilution rate in continuous cultures (yet generally much lower), will also impact the C:P ratio by itself, since with the same concentrations of $\mathrm{P}$ in the inflowing water, high renewal rate will cause reduced C:P (see Sommer, 1992). Also for lakes, seston C:P is negatively correlated with renewal rates (Hecky et al., 1993), yet the analogy with chemostats should be made with some caution, recognising the generally much greater dilution rates in lakes.

Hence, we can identify various patterns in autotroph quantity in terms of $\mathrm{C}$ or $\mathrm{P}$, or quality (from the consumer's perspective) in terms of the ratio between the two (C: $\mathrm{P})$ in lakes which partly reflect the effects of light, $\mathrm{CO}_{2^{\prime}}$ [P] and other lake-specific attributes. The relative importance of these factors for trophic efficiency and secondary production is not straightforward, however.

\section{Quantity- or quality-limitation of zooplankton production?}

To what extent is energy flux in ecosystems and the shape of trophic pyramids governed by quantity or quality at the base of the food web? More specifically, is zooplankton production and biomass in lakes limited by food quantity or quality? Historically, there has been a shift in focus from the quantity aspect to the quality aspect. While the seminal studies on Daphnia ecology and physiology focused on its functional responses related to food quantity (in terms of C) (e.g. Lampert, 1977), they also addressed qualitative aspects related to phytoplankton community composition, size, shape and digestibility. More recently, the nutritional quality such as the ratio of C:P (Hessen, 1992; Urabe \& Watanabe, 1992; Sterner, 1993; Sterner \& Elser, 2002) as well as the content of essential macromolecules, notably essential polyunsaturated fatty acids (PUFAs) or sterols, has been invoked as a key factor for trophic transfer efficiency in lakes (Brett \& Müller-Navarra, 1997; MartinCreuzburg \& von Elert, 2004; Müller-Navarra et al., 2004). Some amino acids are also essential for consumers

a)

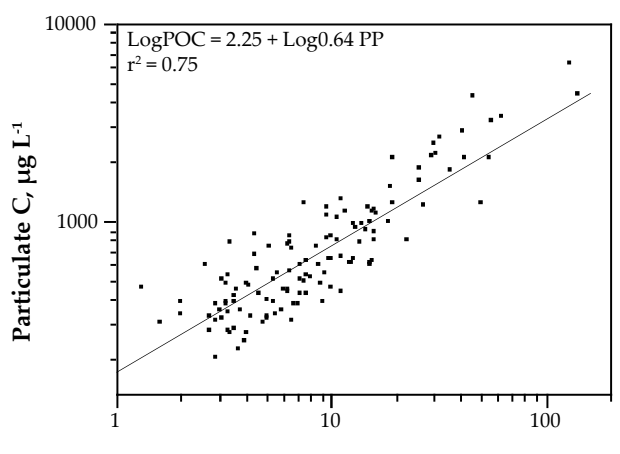

b)

Particulate $P, \mu g \mathrm{~L}^{-1}$

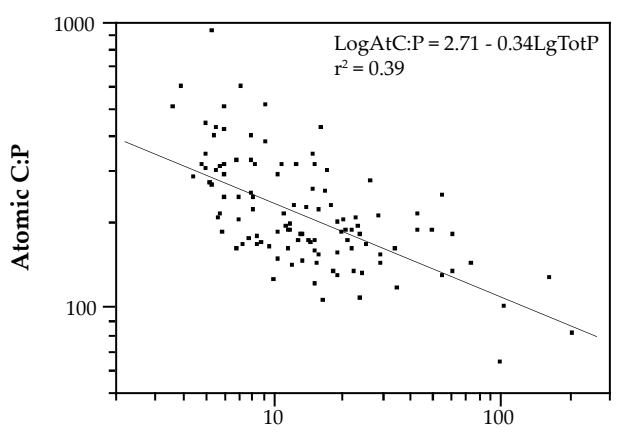

Total $\mathbf{P}, \mu \mathrm{g} \mathrm{L}^{-1}$

Fig. 3. (a) Scatterplot of sestonic concentrations of particulate $C$ over particulate $\mathrm{P}$ in 112 Norwegian lakes, spanning a wide range in productivity (Hessen, 2006). (b) Sestonic atomic C:P-ratios over total $\mathrm{P}$ in the same lakes. 
(Anderson et al., 2004). I shall here focus on the reciprocal effects of $\mathrm{C}$ and C:P for zooplankton nutrition. While $\mathrm{C}$ in absolute terms (concentration) is the conventional measure of quantity, $\mathrm{P}$ in relative terms (e.g. C:P) is the key stoichiometric quality measure for freshwater consumers. The relationship between absolute and relative amounts of $\mathrm{C}$ and $\mathrm{P}$ in food is a crucial factor for energy flow and productivity in food webs.

Judged from the concentrations of edible algae in most lakes, zooplankton should rarely experience maximum growth rates in terms of food quantity. For large-bodied cladocerans like Daphnia, the lower threshold for net positive growth is typically $0.05 \mathrm{mg} \mathrm{C} \mathrm{L}^{-1}$ or lower, while the growth rate approaches an asymptotic level near $2 \mathrm{mg} \mathrm{C} \mathrm{L}^{-1}$ (of high quality food) (Lampert, 1977; Gliwicz \& Lampert, 1993). Copepods have even lower thresholds, while rotifers have generally higher ones. Maximum growth rates are achieved only temporarily in temperate lakes, typically at times of peak spring-bloom, when phytoplankton biomass is high and of good quality and grazer biomass is still low. For the remaining part of the growing season, the zooplankton faces the challenge of coping with either low food quantity, nutritionally deficient food, or both.

This is illustrated conceptually in Fig. 4 where the theoretical boundary for a shift between C- and Plimitation for Daphnia (indicated by the diagonal line) is set to a C:P weight ratio of 90 (atomic C:P-ratio close to 200, see Hessen, 1992; Urabe \& Watanabe, 1992; Sterner, 1993; Anderson \& Hessen, 2005). The threshold for saturated Cintake (indicated by the horizontal line) is set to $2 \mathrm{mg} \mathrm{C} \mathrm{L}^{-1}$. At very low $\mathrm{C}$, a major fraction of ingested $\mathrm{C}$ is allocated to maintenance costs (Sterner \& Robinson, 1994), hence the relative fraction of ingested $C$ that can be utilised for growth will decrease, and consequently the threshold C:Pratio will increase (broken line). However, as demonstrated by Boersma \& Kreutzer (2002) and by Anderson \& Hessen (2005), the threshold C:P-ratio will not rise to infinity even under very low food quantities. Given the range of seston C and C:P-ratios in the exemplified Norwegian lakes (mostly oligotrophic lakes), the largest fraction of lakes offer suboptimal food quantities for Daphnia growth, a fair number of lakes also pose additional constraints by suboptimal food qualities in terms of C:P-ratios. Hence, while most lakes offer suboptimal quantities of grazeable food for zooplankton herbivores, 'co-limitation' by quantity and quality for consumers is also a common phenomenon; when considering other quality aspects of food (morphology, contents of essential fatty acids, sterols, vitamins etc.), some kind of co-limitation is probably the prevailing situation in most lakes, certainly at times.

The boundaries between the different limitation scenarios should thus be judged with caution, because there is a suite of other aspects of food quality that might possibly modify growth rate. Constraint on growth rate could also differ with grazer ontogeny (fast-growing juveniles being most susceptible to any kind of qualitylimitation) and trophic status of the lake. It is also important to keep in mind that growth primarily means protein synthesis, and hence grazers also commonly face $\mathrm{N}$-deficiency (White, 1993). While the focus of this review, as of most of the literature on stoichiometry in pelagic food webs, is on the potential role of deficiency of $\mathrm{P}$ for ribosome synthesis for zooplankton, it should be kept in mind that protein synthesis demands a balanced net intake of both $\mathrm{N}$ and P (Hessen et al., 2007), and a recent meta-

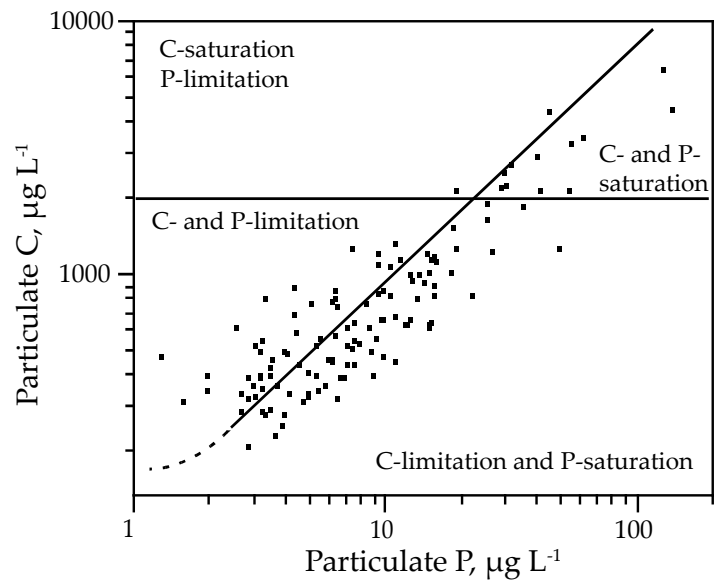

Fig. 4. Conceptual illustration of potential areas for quantity (C) or quality (C:P) limitation for Daphnia. The horizontal line corresponds to the saturating carbon concentration of $2 \mathrm{mg} \mathrm{C} \mathrm{L}^{-1}$ and the diagonal line corresponds to a C:P mass ratio of 90 . Note that these boundaries are no more than tentative (see text for further explanation). This figure is based on the data in Fig. 3. 
analysis strongly suggests that co-limitation of $\mathrm{N}$ and $\mathrm{P}$ for autotrophs is also more common in lakes than hitherto recognised (Elser et al., 2007). Hence, increased attention to N-limitation is recommended for future studies.

In principle, what really matters for the consumer is the net intake of $\mathrm{C}$ and P. Since metazoan consumers, unlike osmotrophic heterotrophs like bacteria, generally experience their food as packages containing both $\mathrm{C}$ and $\mathrm{P}$, the ratio between these elements (i.e. what is defined as the stoichiometric quality) is a good proxy of whether the growth is primarily regulated by the intake of $C$ or by P. While simple stoichiometric models assume a modest efficiency for utilisation of ingested $C$ (i.e. typically a maximum $60 \%$ transfer efficiency from food to grazer), it has been widely assumed that ingested $\mathrm{P}$ is more or less completely reclaimed by the animal. This may not be the case, however, since there are metabolic costs associated with processing of both elements, and this regulation will vary with the quantities and relative proportions of both elements (Boersma \& Kreutzer, 2002; Darchambeu et al., 2003; Anderson et al., 2005). Hence, the predicted transition from C-to P-limitation (see Fig. 4), typically set to an atomic ratio of 200 for P-demanding consumers like Daphnia, will strongly depend on the assimilation efficiency for $\mathrm{C}$ versus $\mathrm{P}$. A lower assimilation efficiency for $\mathrm{C}$ will shift the threshold upwards and vice versa. This again depends on the physiological regulation of net intake of elements and biochemical constituents. I shall not pursue these metabolic aspects of consumer physiology further here, but just point to the different roles of $\mathrm{P}$ and $\mathrm{C}$ related to growth and maintenance since this is essential for understanding the balance between food quantity and quality for consumers.

For unicellular heterotrophs and invertebrates, ribosomal RNA often constitutes a major fraction of body P. Since ribosomes are the site of protein synthesis, this means that Pdeficiency could constrain protein synthesis and, thus, growth rate, suggesting a close positive association between the specific P-content and the growth rate of an organism (Hessen, 1990; Elser et al., 1996). These assumptions seem to be met for a wide range of prokaryotes and arthropods (Vrede et al., 2002; Elser et al., 2003; Acharya et al., 2004a, b; Weider et al., 2005). Thus, in terms of classical life history theory, it can be proposed that, among invertebrates, specific P-content reflects their life history strategy along an $r-K$ continuum. This may not hold for vertebrates, where a major fraction of $\mathrm{P}$ is allocated to bony structures. $\mathrm{P}$ also plays a major role in generating ATP by oxidising organic matter in the TCAcycle, although the sum of ATP, ADP and AMP generally constitutes a minor fraction of the overall cellular P (Sterner \& Elser, 2002). The role of P in building ribosomes and, implicitly, in protein synthesis, also points to the need for balanced intake of $\mathrm{N}$ (building blocks for amino acids and thus proteins) and P. As argued above, only when there is sufficient $\mathrm{N}$ available can the ribosomal biosynthetic machinery run at maximal speed (see Hessen et al., 2007).

Thus, while P serves primarily biosynthetic purposes (with some $\mathrm{P}$ allocated to phospholipids), C (like $\mathrm{N}$ ) primarily serves as a building block, and $C$ is the major constituent in energy-rich storage carbohydrates and lipids. Thus, the intake of both $\mathrm{P}$ and $\mathrm{N}$ is crucial for active growth, but is less important for maintenance metabolism. This means that the importance of C, N and $\mathrm{P}$ may play different roles during an individuals' ontogeny, which has major implications for population dynamics (see below). Typically, fast-growing juveniles may serve as stoichiometric bottle-necks due to their high demands for P (Villar-Argaiz \& Sterner, 2002).

For selective feeders like copepods there is also a possibility for compensatory feeding on food items that are richer in deficient elements (Simpson et al., 2004), and even non-selective feeders like Daphnia could compensate for P-deficiency by vertical migration to layers with more P-rich food (Sterner \& Schwalbach, 2001). At least in theory, organisms could compensate for deficiency of limiting substances by increasing their overall intake rate. This trading of quantity for quality is not trivial, however, since increased intake of food also has metabolic costs. The respiratory costs associated with processing of food (the specific dynamic action, see Lampert, 1977; Jensen \& Hessen, 2007) could offset part of the gain by increased feeding rate, and there is also an upper physiological limit on actual feeding rate. To work efficiently, this kind of compensatory feeding would also imply an enzymatic 
down-regulation of some gut enzymes (e.g. carbohydrases) and up-regulation of others (e.g. phosphatases). The extent to which animals actually can perform this kind of compensatory feeding will obviously vary among species and taxa. For example, Cruz-Rivera \& Hay (2000) tested the ability to compensate for quality deficient food by increased intake rates in three amphipod species, and found that one of the tested species compensated for dietary N-deficiency by increased food intake, while the two others did not.

\section{Trade-off between consumer growth rate and maintenance}

Growth rate and carrying capacity for animal populations may depend on different ecosystem properties. We have seen that not only quantity but also quality of plant matter can have strong impacts on grazers (Sterner \& Elser, 2002), and the relative effects of quantity versus quality are surely interrelated (see Sterner \& Robinson, 1994). High food abundance may also to some extent compensate for low quality and vice versa. The effect of quantity relative to quality also strongly depends on the consumers' demand, and within a species such demands may go through ontogenetic shifts. Juvenile growth may imply different demands than reproduction or maintenance in adults (Villar-Argaiz \& Sterner, 2002; Færøvig \& Hessen, 2003). Correspondingly, the different demands and responses at the individual level may sum up to different demands and responses at the population level.

The prediction of contrasting effects of plant biomass (biomass of $\mathrm{C}$ ) and plant quality (in this context C:P) on herbivores was tested in an experimental chemostat system with the unicellular chlorophyte Selenastrum capricornutum as food and the planktonic cladoceran Daphnia magna as consumer. The experiments were performed in a continuous, two-step culture system, consisting of a primary phototroph chamber and a secondary herbivore chamber (Andersen et al., 2007). Briefly, the primary step used a 2 Lglass vessel with $10 \%$ COMBO-medium (5 $\mu \mathrm{mol}$ $\mathrm{P} \mathrm{L}^{-1}$ ), receiving a nominal, saturating light intensity of $70 \mu \mathrm{mol}$ quanta $\mathrm{m}^{-2} \mathrm{~s}^{-1}$ from $25 \mathrm{~W}$ blue-white fluorescent tubes. A low-light treatment at $36 \mu \mathrm{mol}$ quanta $\mathrm{m}^{-2} \mathrm{~s}^{-1}$ was implemented by increasing the distance from the light source, and by wrapping culture vessels in neutral density filters. Daphnia magna were added to the second chamber (1 L) downstream of the phytoplankton chemostats, after these had run for 7 days. Ten adults were added to each of the replicates, and the population response in Daphnia was assessed over a period of 80 days (Fig. 5).

In line with the experiments of Urabe \& Sterner (1996) and Hessen et al. (2003), the high-light treatment produced twice as high algal biomass as the light-limited treatment. Atomic C:P ratio almost doubled from a mean of 301 at $36 \mu \mathrm{mol}$ quanta $\mathrm{m}^{-2} \mathrm{~s}^{-1}$ to 571 at $70 \mu \mathrm{mol}$ quanta $\mathrm{m}^{-2} \mathrm{~s}^{-1}$, mainly reflecting a strong increase in biomass- $\mathrm{C}$ at high light (17 mg C L $\mathrm{Ls}^{-1} \mathrm{mg} \mathrm{C} \mathrm{L}^{-1}$ at low light), whereas levels of particulate $\mathrm{P}$ were only slightly higher at high light $(73 \mu \mathrm{g}$ $\mathrm{P} \mathrm{L}^{-1}$ vs $60 \mu \mathrm{g} \mathrm{P} \mathrm{L}^{-1}$ ). The grazers also responded strongly to the algal differences in food quantity and quality. There was an almost immediate population growth of Daphnia, and the population receiving algae from the low-light treatment responded more rapidly than the one receiving algae from the high-light treatment. From d 20 onwards, however, the high light treatment yielded a higher Daphnia biomass, which levelled off at approximately $25 \mathrm{mg} \mathrm{C} \mathrm{L}^{-1}$, more than twice that of the low light treatment. Daphnia abundance exceeded 1000 ind $\mathrm{L}^{-1}$ in the high-light treatment and stabilised at a higher abundance than in the low-light treatment. Analysis of mean size (Fig. 5, lower panel) revealed that development was not entirely synchronous in the two treatments, with some deviation between the two parallels at each date and an earlier onset of reproduction in the low-light treatment. The general difference between the two light levels, which was quite pronounced during the first part of the experiment, subsequently became more stable except for the last few days.

As a consequence of increased algal biomass at a finite level of $\mathrm{P}$, the algal C:P-ratio also doubled in the high light treatment, meaning reduced food quality for the consumer. The first part of the experimental period thus confirmed stoichiometric predictions: population growth was slower in the high-light treatment, owing to reduced food quality. It is noteworthy that, in spite of similar concentrations of $\mathrm{P}$ in both treatments, the initial growth 
rate of Daphnia was still reduced in the high light treatment owing to reduced utilisation of ingested $C$ for growth (i.e. more 'excess $C^{\prime}$ going to defecation or respiration). However, as Daphnia biomass built up and approached carrying capacity, the biomass became nearly twice as high in the high-light treatment, reflecting the fact that while low food quality puts a toll on growth rate, it may still

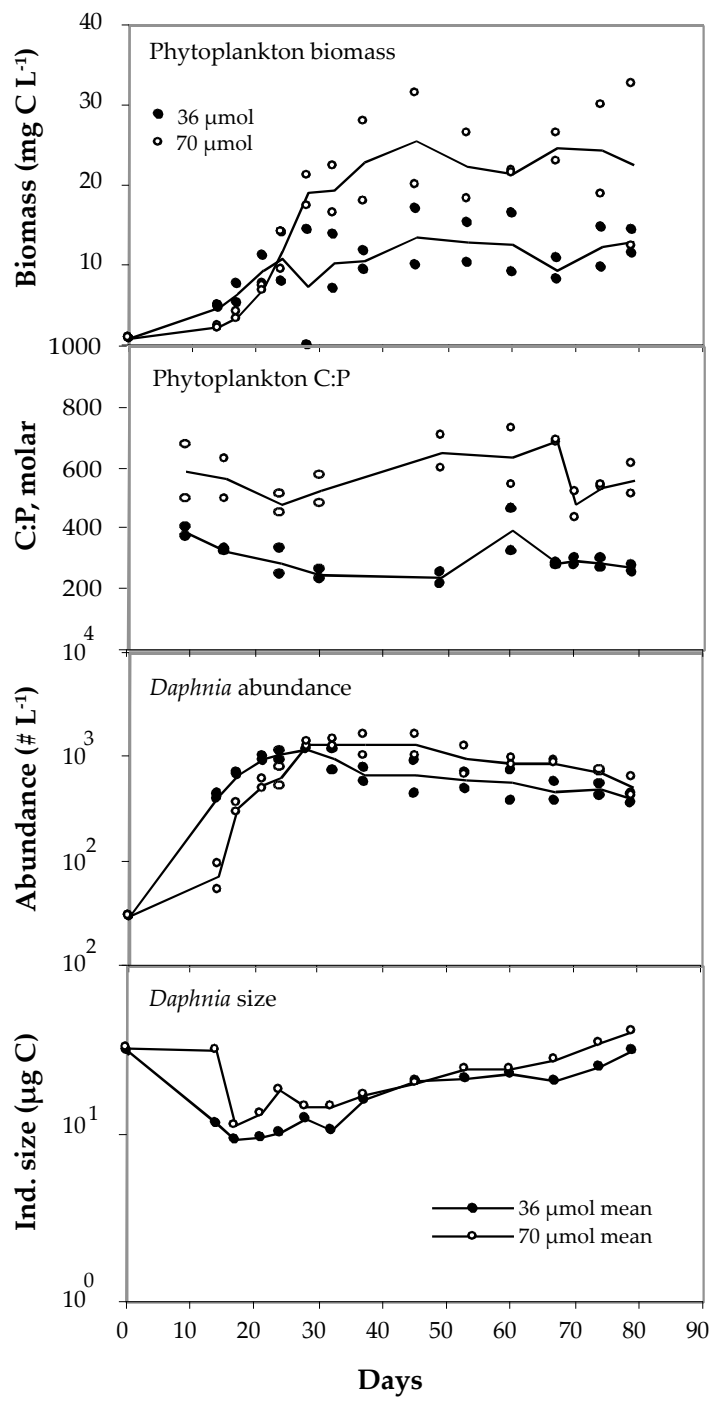

Fig. 5. Long term experiment with two-step chemostat (separated autotroph and grazer growth chamber) demonstrating the different impact of food quantity and quality on population growth and carrying capacity for Daphnia magna. Two replicates of high light treatments (open symbols) yielding high biomass and high $C: P$, and low light treatment (filled symbols) yielding low biomass and low C:P. See text for further details. sustain maintenance (or slow growth) under steady-state conditions. There was also an increased fraction of small animals in the low-light treatment, probably reflecting a higher reproductive output at higher food quality. The different outcomes could not be accredited to different loss rates in the zooplankton chamber, since all individuals were retained in the chamber by a screen on the outlet.

A system where the autotroph and the grazer growth chambers are separated is ideal for testing long-term grazer responses along food-quality and -quantity gradients, but excludes recycling and direct feedback effects from the grazer to the autotroph. These experiments clearly demonstrate that the effects of food quality and quantity will differ, depending on whether one considers the initial or late population responses of the grazer. In pelagic ecosystems, high biomasses of edible phytoplankton and high biomass of herbivores do, however, rarely co-exist for long periods. Hence, to judge the ecological relevance of these observations, we first have to look at the dynamic outcome of plant and grazer interactions in a quality-quantity context.

\section{Feedbacks: stoichiometry, density dependence and facilitation}

In cross-system comparisons, systems with high seston mass caused by high P-concentrations, tend to have higher seston quality (lower C:P ratios) (see Fig. 3). Within systems, however, food quality is often inversely related to food quantity. High biomass and low turnover of phytoplankton commonly yield low nutrient quotas. Grazing not only affects plant quantity, it may also affect the plant quality in two qualitatively different ways. First, increased grazing could cause decreased food quality because the most nutritious plant material is removed, leaving the low quality vegetation behind (see Turchin, 2003). Alternatively, grazing could trigger inducible defences (Tollrian \& Harvell, 1999) that would lower grazer fitness. This would again reinforce density dependence, since grazers would face the double challenge of both reduced quantity and quality of food. However, quite the opposite effect may also occur: increased grazing can cause 
improved food quality in a form of facilitation that may operate by different mechanisms.

In stoichiometric facilitation, grazer-mediated coupling between plant quantity and its quality causes positive density dependence in grazers (i.e. net growth rate increases with population density up to a certain level). The grazers crop the autotroph biomass, thus reducing the number of algal cells in which a given amount of nutrients can be diluted. Simultaneously, nutrients recycled from the grazers can be acquired by the remaining autotroph biomass. This will be beneficial to the grazers, both from a plant quantity and a plant quality perspective. The initial stoichiometric conditions are important, as such effects will only be seen if herbivores are initially constrained by low nutrient content in the autotrophs.

An illuminating example of stoichiometric facilitation was provided by Sommer (1992). Grazers (Daphnia galeata) were introduced to continuous, large-volume (10 L) algal cultures with Scenedesmus acutus grown to steady state under $\mathrm{P}$ limitation at different dilution rates. In the lowdilution cultures, where algal C:P was very high, Daphnia failed to establish but they showed positive population growth in Scendesmus cultures grown at slightly higher dilution rates and lower C:P-ratios. Sommer (1992) showed convincingly that this outcome was caused by different food $P$ content rather than differences in food quantity between cultures. The increasing Daphnia population reduced both particulate P- and C-levels, but to different extents, such that the $\mathrm{P}: \mathrm{C}$ ratio of particulate matter actually increased. As Daphnia biomass slowly accumulated in this initially poor-quality scenario, both somatic growth rates and eggproduction rates increased, resulting in a positive relationship between net growth rate and Daphnia abundance. This is a transient situation, however, as further build-up of grazer biomass eventually reduces the food C:P ratio to levels below the threshold, returning the system to energy limitation and 'normal' negative density dependence. A corresponding scenario, albeit over longer time scales, was documented by Urabe et al. (2002). It should be noted that these responses differ from what would be predicted by traditional Lotka-Volterra predator-prey models that take only quantities of food and consumer into account.
One very intriguing outcome of grazer-resource models, in which stoichiometric constraints on the grazer as well as nutrient-cycling facilitation effects are taken into consideration, is the potential for deterministic extinction of the grazer even at high food abundance. In principle, stoichiometric constraints on the grazer at very high algal C:P ratios may induce a quality starvation and eventually extinction of the grazer, if the growth rate becomes too low to compensate for the death rate and other losses. If the quality is slightly higher, the cropping of phytoplankton biomass combined with release of nutrients will gradually cause a lower biomass of algae with improved nutritional quality. This will again be beneficial to the grazer, until eventually the algal biomass is cropped down to very low levels where the zooplankton experience severe starvation due to low food quantity. The model output of such scenarios is exemplified in Andersen et al. (2004) and Diehl (2007) where there are oscillations in phytoand zooplankton biomass, and where the zooplankton experiences brief periods of assumed happiness, but else is squeezed between quantity and quality limitations. By making the models slightly more sophisticated through the inclusion of a third trophic level, it seems likely that grazers could also run into nutrient limitation at higher nutrient supply levels (Hall et al., 2007). As always, one should be aware that such simplified models, like the results of laboratory experiments under simplified conditions, are inadequate in catching the complex dynamics in the real world. This is not to say that simple experiments and models are irrelevant or academic. In fact, many of the basic principles and processes that in sum make up complex ecosystems can only be revealed by isolating single phenomena and simple interactions.

\section{Relevance for natural systems and lake management}

So, where does all this take us? To what extent is this relevant to lake ecosystems and to various aspects of lake ecosystem management? The main take-home message is that plant biomass may bea poor predictor of yield to higher trophic levels, due to various quality constraints, of which 
the ratio of C:P at the base of the food web could be one such major factor. While much emphasis on stoichiometric constraints of grazers has been devoted to fresh waters, terrestrial grazers should be even more susceptible to $\mathrm{P}$ or $\mathrm{N}$-limitation as judged from the mismatch of C:P or C:N ratios between terrestrial autotrophs and grazers (Elser et al., 2000).

A very intriguing finding is the counterintuitive response to light levels. In general, productivity and carrying capacity of pelagic systems can be predicted from the inputs of light and nutrients (see Reynolds, 1999). Increased light (but below stress levels) would give more plant biomass, which again would yield more herbivore biomass. However, when there is excess C-fixation owing to high light levels or high $\mathrm{CO}_{2}$ concentrations relative to nutrient availability, the effect of the consumer response on autotroph biomass may be non-linear. The innovative studies of Urabe \& Sterner (1996) and confirmatory studies from other laboratory experiments or enclosure studies (Sterner et al., 1998; Hessen et al., 2002; Urabe et al., 2002) demonstrate that there could be a hump-shaped response on increasing light intensity, with peak zooplankton productivity at medium light intensities. The magnitude of this effect will depend on the ambient P-concentration and on the ability of plants to vary their cellular C:P ratios, but it seems to be a phenomenon that could be highly relevant for lakes, especially under oligotrophic conditions (see Diehl, 2007).

Another striking outcome of the stoichiometric predictions is that the 'quality starvation', or P limitation, may be sufficiently severe to exclude key pelagic grazers like the P-demanding daphnids. Lack of Daphnia could be attributable in some localities to such effects, yet they are not likely to be very widespread, since C:P ratios must be truly extreme for such effects to occur. More commonly this kind of quality starvation could be a transient phenomenon during seasonal succession (Jäger et al., 2008), and most likely to occur at periods of high C:P, implying a strong competitive drawback for the most P-demanding species.

Increased $\mathrm{P}$ load also seems to give contrasting responses within and between lakes. A pulsed addition of $P$ will lower C:P ratio (and, from the grazers' perspective, to more favourable levels) only temporarily, before increased biomass accumulation by C-fixation again dilutes the internal algal stores of $\mathrm{P}$ and causes elevated C:P. The fact that increased $\mathrm{P}$ gives reduced C:P when comparing lakes must reflect a generally higher availability of $\mathrm{P}$ in the more productive localities, probably due to recycling or continuous input of $\mathrm{P}$ from the sediment or catchment. On the other hand, eutrophication is known to produce lower seston quality. The most obvious changes have been seen in the phytoplankton community where a transition from small, edible algae to larger and less edible diatoms, chlorophytes and filamentous, toxic and PUFA-deficient Cyanobacteria is a frequent result of eutrophication. These autotrophs, and Cyanobacteria in particular, are poor food for most zooplankton species (Lampert, 1977; Watson \& Kalff, 1981), resulting in reduced slopes of trophic pyramids due to reduced trophic transfer efficiency with less energy transferred to higher trophic levels (McCauley \& Kalff, 1981; McCauley et al., 1989; Jeppesen et al., 2000, 2003). The 'excess' primary production that accumulates and sinks as ungrazed biomass is a key problem caused by eutrophication, eventually leading to hypolimnetic $\mathrm{O}_{2}$-depletion and internal P-release from sediments.

It would therefore be assumed that there is a tradeoff between positive and negative quality effects with increased nutrient load and, thus, that a unimodal relationship could be expected in the ratio between phyto- and zooplankton along a gradient of ambient P. The positive but sigmoid relationship between phytoplankton and total zooplankton biomass that has been found along gradients of lake productivities suggests a decreased trophic efficiency with system enrichment (McCauley \& Kalff, 1981; Hanson \& Peters, 1984; McQueen et al., 1986), yet one should keep in mind that biomass ratios may differ from productivity ratios.

Finally, in a 'global change' context, the stoichiometric perspective could also provide some insight into the fate of the extra $\mathrm{CO}_{2}$-input to fresh waters, either directly due to increased atmospheric $\mathrm{CO}_{2}$, or indirectly from increased load of DOC. Besides potentially causing a drop in $\mathrm{pH}$ in low-buffered waters, experiments with $\mathrm{CO}_{2}$-enrichments have shown the potential for elevated C: 
P-ratios, for analogous reasons to those mediated by high light intensity: the disproportionate uptake of $C$ relative to P (Urabe et al., 2003; Hessen et al., 2004). Elevated $\mathrm{CO}_{2}$ levels potentially support elevated concentrations of seston but of lower quality. This could dampen oscillations in a resource-consumer system, since it would promote slower growth of consumers. However, the outcome of energy enrichment on system stability is not straightforward (Diehl, 2007). Another aspect of climate change that is most likely to affect seston quality is the input of allochthonous dissolved organic carbon. The latter is likely to increase with increased warming combined with increased runoff (Skjelkvåle et al., 2005) but, equally, could decrease through increased drought (Schindler et al., 1997). More DOC will first of all increase $\mathrm{pCO}_{2}$, owing to increased microbial activity (Hessenetal., 1990; del Giorgio \& Peters, 1994; Sobek et al., 2003), and could also directly increase the fraction of detritus and heterotrophs in the seston, causing a decreased production:respiration ratio at the ecosystem level. Higher levels of DOC would also strongly affect the light regime in individual lakes and the lower light levels could promote lower C:P ratios. Since coloured water heats more rapidly, however, it would also imply a shallower epilimnion that could cancel out the effects of increased light attenuation.

Large-scale differences in trophic efficiency and carbon flux exist between ecosystems, the highest efficiencies, by far, being in pelagic habitats (Cebrian, 1999). These differences are partly accredited to the small size of the pelagic autotrophs, their reduced need for structural tissue and their high nutrient quotas (low C:P or C:N) and thus high growth rates. However, even if trophic efficiency is far higher in pelagic habitats compared with littoral and terrestrial ecosystems, they too vary a lot in their Ctransfer efficiency across trophic levels. Biomass ratios between autotrophs and grazers may vary tenfold within the same level of nutrient supply and fish community class, probably reflecting a strong variability also in trophic efficiency (Hessen et al., 2006). Clearly the biomass ratios between phyto- and zooplankton in lakes reflect top-down impacts from fish predation as well as bottom-up effects due to algal community composition (i.e. edibility and morphology). There is, however, also reason to believe that much of the cause for this variability hinges on the autotroph cell quotas of nutrients that have been shown to profoundly affect carbon-use efficiency in grazers (Sterner \& Elser, 2002), as well as other quality aspects of food correlated with autotroph community composition.

As a concluding remark, it could be tempting to paraphrase an old saying and claim that, even armed with the stoichiometric insight, we are still confused, but at a higher level. That would not be entirely fair, however. Ecology, in general, and food web responses in particular, are notoriously complex. By taking the quality aspect of food into account along with the quantity aspect, we are surely better equipped to judge the interaction between the players in the ecological theatre, and also better prepared to judge the future effects of human impact on the ecosystems.

\section{Acknowledgements}

Data used in this review originate from collaborative projects with Tom Andersen, Bjørn Faafeng, Per J. Færøvig and Ellen van Donk. Thanks to all for cooperation and discussions through various projects. This ms. has been improved substantially by the most thorough and helpful comments from Sebastian Diehl and an anonymous reviewer.

\section{References}

Acharya, K., Kyle, M. \& Elser, J.J. (2004a). Biological stoichiometry in Daphnia growth: an ecophysiological test of the growth rate hypothesis. Limnology \& Oceanography 49, 656-665.

Acharya, K., Kyle, M. \& Elser, J.J. (2004b). Effects of stoichiometric dietary mixing on Daphnia growth and reproduction. Oecologia 138, 1432-1439.

Andersen, T., Elser, J.J. \& Hessen, D.O. (2004). Stoichiometry and population dynamics. Ecology Letters 7, 884-900.

Andersen, T., Færøvig, P.J. \& Hessen, D.O. (2007). Zooplankton carrying capacity as related to quality and quantity of food. Limnology \& Oceanography 52, 2128-2134.

Anderson, T.R. \& Hessen, D.O. (2005). Threshold elemental ratios for carbon versus phosphorus limitation in Daphnia. Freshwater Biology 50, 2063-2075. 
Anderson, T.R., Boersma, M. \& Raubenheimer, D. (2004). Stoichiometry: linking elements to biochemicals. Ecology 85, 1193-1202.

Anderson, T.R., Hessen, D.O., Elser, J.J. \& Urabe, J. (2005). Metabolic stoichiometry and the fate of excess carbon and nutrients in consumers. The American Naturalist 165, 1-15.

Berger, S.A., Diehl, S., Kunz, T.J., Albrecht, D., Oucible, A.M. \& Ritzer, S. (2006). Light supply, plankton biomass and seston stoichiometry in a gradient of lake mixing depths. Limnology and Oceanography 51, 1898-1905.

Boersma, M. \& Kreutzer, C. (2002). Life at the edge: is food quality really of minor importance at low quantities? Ecology 83, 25522561.

Brett, M.T. \& Müller-Navarra, D.C. (1997). The role of highly unsaturated fatty acids in aquatic food web processes. Freshwater Biology 38, 483-499.

Carpenter, S.R. \& Kitchell, J.F. (eds) (1993). The Trophic Cascade in Lakes. Cambridge University Press, Cambridge. 385pp.

Carpenter, S.R., Cole, J.J., Hodgson, J.R., Kitchell, J.F., Pace, M.L., Bade, D., Cottingham, K.L., Essington, T.E., Houser, J.N. \& Schindler, D.E. (2001). Trophic cascades, nutrients, and lake productivity: whole lake experiments. Ecological Monographs 71, 163-186.

Cebrian, J. (1999). Patterns in the fate of production in plant communities. The American Naturalist 154, 449-468.

Cruz-Rivera, E. \& Hay, M.E. (2000). Can quantity replace quality? Food choice, compensatory feeding, and fitness of marine mesograzers. Ecology 81, 201-219.

Darchambeau, F., Færøvig, P.J. \& Hessen, D.O. (2003). How Daphnia copes with excess carbon in its food. Oecologia 136, 336-346.

del Giorgio, P.A. \& Peters, R.H. (1994). Patterns in planktonic P:R ratios in lakes: influence of lake trophy and dissolved organic carbon. Limnology \& Oceanography 39, 772-787.

Diehl, S. (2007). Paradoxes of enrichment: effects of increased light versus nutrient supply on pelagic producer-grazer systems. The American Naturalist 169, E173-E191.

Diehl, S., Berger, S., Ptacnik, R. \& Wild, A. (2002). Phytoplankton, light, and nutrients in a gradient of mixing depths: field experiments. Ecology 83, 399-411.

Elser, J.J. \& Hassett, R.P. (1994). A stoichiometric analysis of the zooplankton-phytoplankton interaction in marine and freshwater ecosystems. Nature 370, 211-213.
Elser, J.J., Dobberfuhl, D., MacKay, N.A. \& Schampel, J.H. (1996). Organism size, life history, and N:P stoichiometry: towards a unified view of cellular and ecosystem processes. BioScience $\mathbf{4 6}$, 674-684.

Elser, J.J., Fagan, W.F., Denno, R.F., Dobberfuhl, D.R., Folarin, A., Huberty, A., Interlandi, S., Kilham, S.S., McCauley, E., Schulz, K.L., Siemann, E.H. \& Sterner, R.W. (2000). Nutritional constraints in terrestrial and freshwater food webs. Nature 408, 578-580.

Elser, J.J., Frost, P., Kyle, M., Urabe, J. \& Andersen, T. (2002). Effects of light and nutrients on plankton stoichiometry and biomass in a P-limited lake. Hydrobiologia 481, 101-112.

Elser, J.J., Acharya, K., Kyle, M., Cotner, J., Makino, W., Markow, T., Watts, T., Hobbie, S., Fagan, W., Schade, J., Hood, J. \& Sterner, R.W. (2003). Growth rate-stoichiometry couplings in diverse biota. Ecology Letters 6, 936-943.

Elser, J.J., Bracken, M.E.S., Cleland, E.E., Gruner, D.S., Harpole, W.S., Hillebrand, H., Ngai, J.T., Seabloom, E.W., Shurin, J.B. \& Smith, J.E. (2007). Global analysis of nitrogen and phosphorus limitation of primary producers in freshwater, marine and terrestrial ecosystems. Ecology Letters 10, 1135-1142.

Færøvig, P.J. \& Hessen, D.O. (2003). Allocation strategies in crustacean stoichiometry: the potential role of phosphorus in the limitation of reproduction. Freshwater Biology 48, 1782-1792.

Gliwicz, Z.M. \& Lampert, W. (1993). Body-size related survival of cladocerans in a trophic gradient: an enclosure study. Archiv für Hydrobiologie 129, 1-23.

Gulati, R.D., Lammens, E.H.R.R., Meijer, M.L. \& van Donk, E. (eds) (1990). Biomanipulation - Tool for Water Management. Hydrobiologia 200/201. 628pp.

Hairston, N.G., Smith, F.E. \& Slobodkin, L.B. (1960). Community structure, population control and competition. The American Naturalist 94, 421-425.

Hall, S.R., Shurin, J.B., Diehl, S., Nisbet, R.M. (2007). Food quality, nutrient limitation of secondary production, and the strength of trophic cascades. Oikos 116, 1128-1143.

Hanson, J.M. \& Peters, R.H. (1984). Empirical prediction of crustacean zooplankton biomass and profundal macrobenthos biomass in lakes. Canadian Journal of Fisheries and Aquatic Sciences 41, 439-445.

Hecky, R.E., Campbell, P. \&Hendzel, L.L. (1993). The stoichiometry of carbon, nitrogen and phosphorus in particulate matter of lakes and oceans. Limnology \& Oceanography 38, 709-724. 
Hessen, D.O. (1990). Carbon, nitrogen and phosphorus status in Daphnia at varying food conditions. Journal of Plankton Research 12, 1239-1249.

Hessen, D.O. (1992). Nutrient element limitation of zooplankton production. The American Naturalist 140, 799-814.

Hessen, D.O. (2006). Determinant of seston C:P-ratio in lakes. Freshwater Biology 51, 1560-1569.

Hessen, D.O., Andersen, T. \& Lyche, A. (1990). Carbon metabolism in a humic lake; pool sizes and cycling through zooplankton. Limnology E Oceanography 35, 84-99.

Hessen, D.O., Færøvig, P.J. \& Andersen, T. (2002). Light, nutrients, and $\mathrm{P}: \mathrm{C}$ ratios in algae: grazer performance related to food quality and quantity. Ecology 83, 1886-1898.

Hessen, D.O., Andersen, T., Brettum, P. \& Faafeng, B.A. (2003). Phytoplankton contribution to sestonic mass and elemental ratios in lakes: implications for zooplankton nutrition. Limnology \& Oceanography 48, 1289-1296.

Hessen, D.O., Ågren, G.I., Anderson, T.R., Elser, J.J. \& de Reuter, P.C. (2004). Carbon sequestration in ecosystems: the role of stoichiometry. Ecology 85, 1179-1192.

Hessen, D.O., van Donk, E. \& Gulati, R. (2005). Seasonal seston stoichiometry: effects on zooplankton in cyanobacteriadominated lakes. Journal of Plankton Research 27, 449-460.

Hessen, D.O., Faafeng, B.A., Brettum, P. \& Andersen, T. (2006). Nutrient enrichment and planktonic biomass ratios in lakes. Ecosystems 9, 516-527.

Hessen, D.O., Jensen, T.C., Kyle, M. \& Elser, J.J. (2007). RNA responses to $\mathrm{N}$ - and P-limitation; reciprocal regulation of stoichiometry and growth rate in Brachionus. Functional Ecology 21, 956-962.

Huisman, J., van Oostveen, P. \& Weissing, F.J. (1999). Species dynamics in phytoplankton blooms: incomplete mixing and competition for light. The American Naturalist 154, 46-68.

Jäger, C.G., Diehl, S., Matauschek, C., Klausmeier, C.A. \& Stibor, H. (2008). Transient dynamics of pelagic producer-grazer systems in a gradient of nutrients and mixing depths. Ecology (in press).

Jensen, T.C. \& Hessen, D.O. (2007). Does excess dietary carbon affect respiration in Daphnia? Oecologia 152, 191-200.

Jeppesen, E., Jensen, J.P., Søndergaard, M., Lauridsen, T. \& Landkildehus, F. (2000). Trophic structure, species richness and biodiversity in Danish lakes; changes along a phosphorus gradient. Freshwater Biology 45, 201-218.
Jeppesen, E., Jensen, J.P., Jensen, C., Faafeng, B., Hessen, D.O., Søndergaard, M., Lauridsen, T., Brettum, P. \& Christoffersen, K. (2003). The impact of nutrient state and lake depth on topdown control in the pelagic zone of lakes: a study of 466 lakes from the temperate zone to the Arctic. Ecosystems 6, 313-325.

Kunz, T.J. \& Diehl, S. (2003). Phytoplankton, light and nutrients along a gradient of mixing depth: a field test of producerresource theory. Freshwater Biology 48, 1050-1063.

Lampert, W. (1977). Studies on the carbon balance of Daphnia pulex de Geer as related to environmental conditions. I-IV. Archiv für Hydrobiologie Beiheft Series 48, 287-368.

Lee, K.P., Raubenheimer, D. \& Simpson, S.J. (2004). The effects of nutritional imbalance on compensatory feeding for cellulosemediated dietary dilution in a generalist caterpillar. Physiological Entomology 29, 108-117.

Martin-Creuzburg, D. \& von Elert, E. (2004). Impact of 10 dietary sterols on growth and reproduction of Daphnia galeata. Journal of Chemical Ecology 30, 483-499.

McCauley, E. \& Kalff, J. (1981). Empirical relationships between phytoplankton and zooplankton biomass in lakes. Canadian Journal of Fisheries and Aquatic Sciences 38, 458-463.

McCauley, E., Downing, J.A. \& Watson, S. (1989). Sigmoid relationships between nutrients and chlorophyll among lakes. Canadian Journal of Fisheries and Aquatic Sciences 46, 1171-1175.

McQueen, D.J., Post, J.R. \& Mills, E.L. (1986). Trophic relationships in freshwater pelagic ecosystems. Canadian Journal of Fisheries and Aquatic Sciences 43, 1571-1581.

Moran, N. \& Hamilton, W.D. (1980). Low nutritive quality as defence against herbivores. Journal of Theoretical Biology 86, 247-254.

Müller-Navarra, D.C., Brett, M.T., Park, S., Chandra, S., Ballantyne, A.P., Zorita, E. \& Goldman, C.R. (2004). Unsaturated fatty acid content in seston and tropho-dynamic coupling in lakes. Nature $427,69-72$

Oksanen, L. (1988). Ecosystem organization: mutualism and cybernetics or plain Darwinian struggle for existence? The American Naturalist 131, 424-444.

Reynolds, C.S. (1999). Metabolic sensitivities of lacustrine ecosystems to anthropogenic forcing. Aquatic Sciences 61, 183205.

Schindler, D.W. (1977). Evolution of phosphorus limitation in lakes. Science 195, 260-262.

Schindler, D.W., Curtis, P.J., Bayley, S.E., Parker, B., Beaty, K.G. \& 
Stainton, M.P. (1997). Climate-induced changes in the dissolved organic carbon budgets of boreal lakes. Biogeochemistry 36, 9-28. Skjelkvåle, B.L., Stoddard, J.L., Jeffries, D.S., Tørseth, K., Høgåsen, T., Bowman, J., Mannio, J., Monteith, D.T., Mosello, R., Rogora, M., Rzychon, D., Vesely, J., Wieting, J., Wilander, A. \& Worsztynowicz, A. (2005). Regional scale evidence for improvements in surface water chemistry 1990-2001. Environmental Pollution 137, 165-176. Sobek, S., Algesten, G., Bergström, A.-K., Jansson, M. \& Tranvik, L.J. (2003). The catchment and climate regulation of $\mathrm{pCO}_{2}$ in boreal lakes. Global Change Biology 9, 630-641.

Sommer, U. (1992). Phosphorus-limited Daphnia - intraspecific facilitation instead of competition. Limnology $\mathcal{E}$ Oceanography 37, 966-973.

Sterner, R.W. (1993). Daphnia growth on varying quality of Scenedesmus: mineral limitation of zooplankton. Ecology 74, 2351-2360.

Sterner, R.W. \& Elser, J.J. (2002). Ecological Stoichiometry: the Biology of Elements from Molecules to the Atmosphere. First edition. Princeton University Press. 439pp.

Sterner, R.W. \& Robinson, J.L. (1994). Thresholds for growth in Daphnia magna with high and low phosphorus diets. Limnology E Oceanography 39, 1228-1232.

Sterner, R.W. \& Schwalbach, M.S. (2001). Diel integration of food quality by Daphnia: luxury consumption by a freshwater planktonic herbivore. Limnology \& Oceanography 46, 410-416.

Sterner, R.W., Elser, J.J., Fee, E.J., Guildford, S.J. \& Chrzanowski,

T.H. (1997). The light:nutrient ratio in lakes: the balance of energy and materials affects ecosystem structure and process. The American Naturalist 150, 663-684.

Sterner, R.W., Clasen, J., Lampert, W. \& Weisse, T. (1998). Carbon: phosphorus stoichiometry and food chain production. Ecology Letters 1, 146-150.

Sterner, R.W., Andersen, T., Elser, J.J., Hessen, D.O., Hood, J.M., McCauley, E. \& Urabe, J. (2008). Scale-dependent C: $\mathrm{N}: \mathrm{P}$ stoichiometry in marine and freshwaters. Limnology $\mathcal{E}$ Oceanography (in press).

Tollrian, R. \& Harvell, C.D. (eds) (1999). The Ecology and Evolution of Inducible Defenses. Princeton University Press. 395 pp.

Turchin, P. (2003). Complex Population Dynamics. Monographs in Population Biology 35, Princeton University Press. 456pp.

Urabe, J. \& Sterner, R.W. (1996). Regulation of herbivore growth by the balance of light and nutrients. Proceedings of the National

\section{Academy of Sciences 93, 8465-8469.}

Urabe, J. \& Watanabe, Y. (1992). Possibility of N or P limitation for planktonic cladocerans: an experimental test. Limnology $\mathcal{E}$ Oceanography 37, 244-251.

Urabe, J., Elser, J.J., Kyle, M., Yoshida, T., Sekino, T. \& Kawabata, Z. (2002). Herbivorous animals can mitigate unfavorable ratios of energy and material supplies by enhancing nutrient recycling. Ecology Letters 5, 177-185.

Urabe, J., Togari, J. \& Elser, J.J. (2003). Stoichiometric impacts of increased carbon dioxide on a planktonic herbivore. Global Change Biology 9, 818-825.

Villar-Argaiz, M. \& Sterner, R.W. (2002). Life history bottlenecks in Diaptomus clavipes induced by phosphorus-limited algae. Limnology \& Oceanography 47, 1229-1233.

Vrede, T., Persson, J. \& Aronsen, G. (2002). The influence of food quality (P:C ratio) on RNA: DNA ratio and somatic growth rate of Daphnia. Limnology E Oceanography 47, 487-494.

Watson, S. \& Kalff, J. (1981). Relationships between nannoplankton and lake trophic status. Canadian Journal of Fisheries and Aquatic Sciences 38, 960-967.

Weider, L.J., Elser, J.J., Crease, T.J., Mateos, M., Cotner, J.B. \& Markow, T.A. (2005). The functional significance of ribosomal rDNA variation: impacts on the evolutionary ecology of organisms. Annual Review of Ecology and Systematics 36, 219-242.

White, T.C.R. (1993). The Inadequate Environment: Nitrogen and the Abundance of Animals. Springer-Verlag, New-York. 425pp.

\section{Author Profile}

The author has been employed as a full professor in Biology at the University of Oslo since 1993, where he also did his masters on food web effects of eutrophication and his $\mathrm{PhD}$ on carbon cycling in humic lakes (1988). From 1988-1992 he worked at the Norwegian Institute for Water Research. His main field of research is in ecological stoichiometry, from the gene level to ecosystems, primarily using Daphnia as a model organism, but he has ongoing projects on a wide range of topics including effects of UV and PAR in arctic freshwater and marine ecosystems, catchment studies on carbon cycling and laboratory studies on growth rate regulation, RNA/DNA-ratios and polyploidy in invertebrates. 